\title{
Correction to: The Opioid Epidemic in Africa and Its Impact
}

\section{Ann E. Kurth ${ }^{1} \cdot$ Peter Cherutich $^{2} \cdot$ Rosabelle Conover $^{1} \cdot$ Nok Chhun $^{1} \cdot$ R. Douglas Bruce ${ }^{3,4} \cdot$ Barrot H. Lambdin ${ }^{5}$}

Published online: 13 August 2019

(C) Springer Nature Switzerland AG 2019

\section{Correction to: Current Addiction Reports (2018) 5:428-453 https://doi.org/10.1007/s40429-018-0232-9}

The original article unfortunately contained a mistake. Under the section "Funding," the following text should have been:

The project described was supported by Grant Number R01DA032080 from the National Institute On Drug Abuse. The content is solely the responsibility of the authors and does not necessarily represent the official views of the National Institute On Drug Abuse or the National Institutes of Health.

Publisher's Note Springer Nature remains neutral with regard to jurisdictional claims in published maps and institutional affiliations.

The online version of the original article can be found at https://doi.org/ 10.1007/s40429-018-0232-9

Ann E. Kurth

ann.kurth@yale.edu

1 Yale University School of Nursing, 400 West Campus Drive, Orange, CT, USA

2 Ministry of Health, Nairobi, Kenya

3 Cornell Scott-Hill Health Center, New Haven, CT, USA

4 Yale University School of Medicine, New Haven, CT, USA

5 RTI International, Research Triangle Park, NC, USA 